Supporting Information for:

\title{
Carbon Nanotube Based Radio Frequency Transistors for K Band Amplifiers
}

Jianshuo Zhou, ${ }^{\dagger}$ Lijun Liu, ${ }^{\dagger}$ Huiwen Shi, ${ }^{\dagger},+$ Maguang Zhu, ${ }^{\dagger}$ Xiaohan Cheng, ${ }^{\dagger, \dagger}$ Li Ren, ${ }^{\dagger}$ Li Ding, ${ }^{\dagger}, *$ Lian-Mao Peng ${ }^{\dagger, \dagger}$ and Zhiyong Zhang ${ }^{\dagger, *}$

$\uparrow$ Key Laboratory for the Physics and Chemistry of Nanodevices and Center for Carbon-based Electronics, Department of Electronics, Peking University, Beijing 100871, China.

* Academy for Advanced Interdisciplinary Studies, Peking University, Beijing 100871, China

*Correspondence to: 1ding@pku.edu.cn, zyzhang@pku.edu.cn.

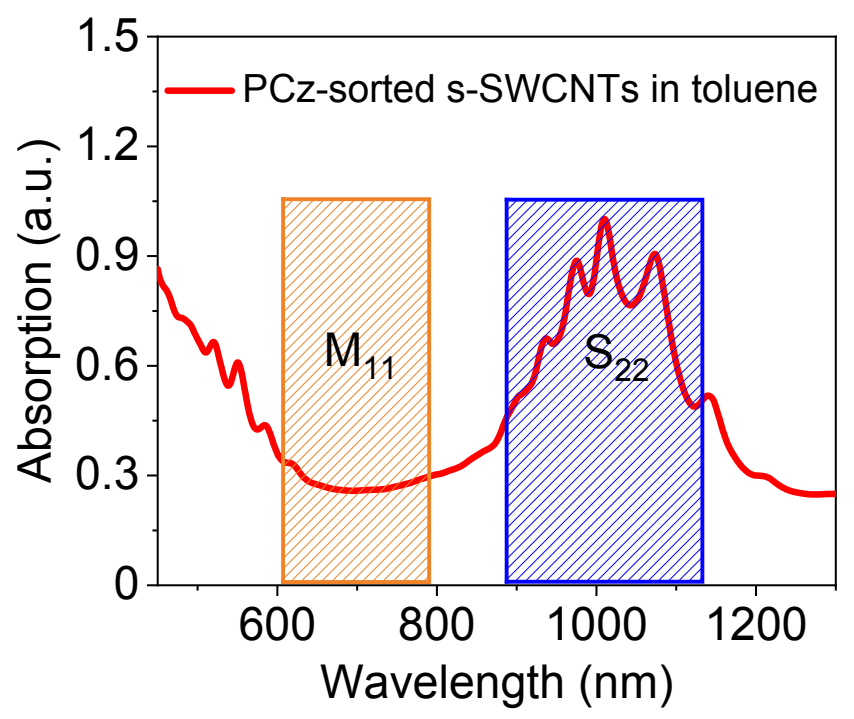

Figure S1 Absorption spectra of CNTs, which the high S22-band/M11-band ratio suggests the CNTs are of high semiconducting purity. 


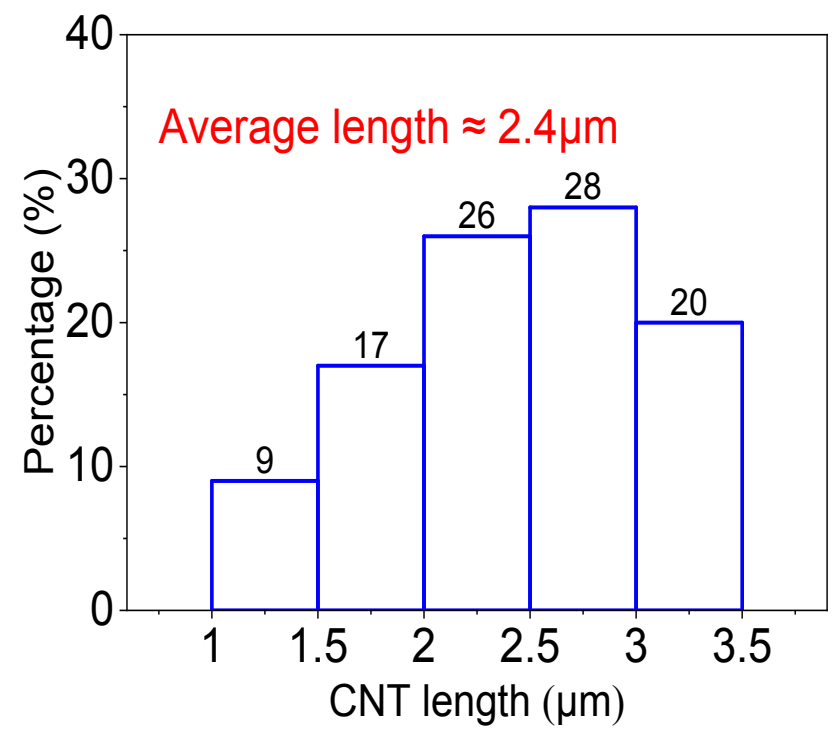

Figure S2 Length distribution of 100 single-wall CNTs measured by SEM, which suggests that the CNTs used in this work have longer tube length than previously reported $2 \mu \mathrm{m}$.

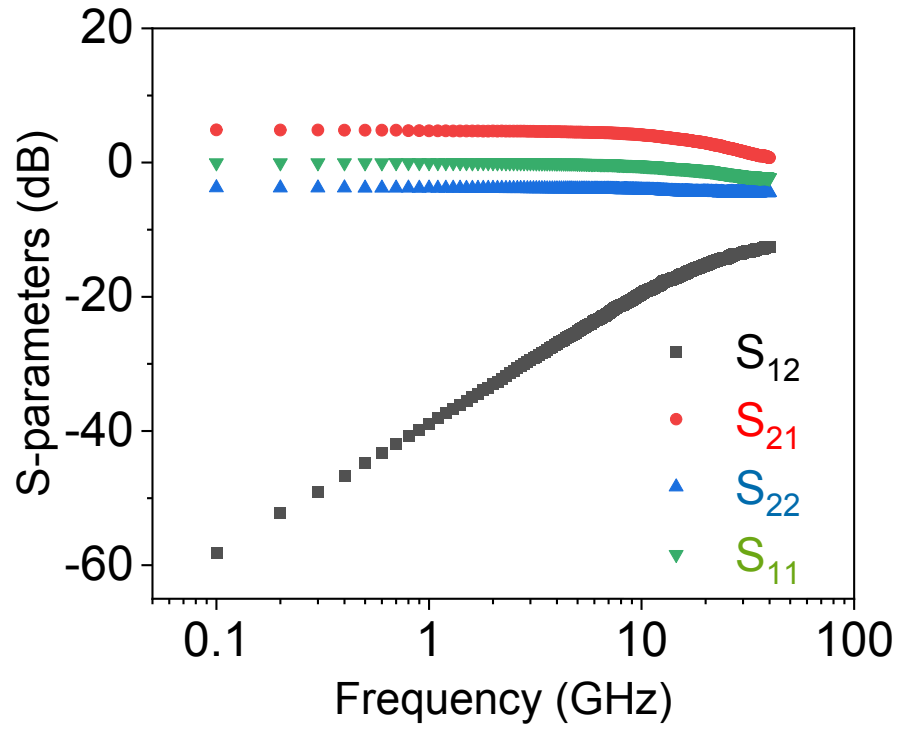

Figure S3. The measured two-port scattering parameters $\left(S_{11}, S_{12}, S_{21}, S_{22}\right)$ versus frequency of a CNT $\mathrm{RF}$ transistor with gate length of $80 \mathrm{~nm}$ at $V_{\mathrm{ds}}$ of $-1.35 \mathrm{~V}$ and $V_{\mathrm{gs}}$ of $-0.6 \mathrm{~V}$. The scanning frequency is from $100 \mathrm{MHz}$ to $40 \mathrm{GHz}$ with a step of $100 \mathrm{MHz}$. The parameters are measured via a vector network 
analyzer (VNA).
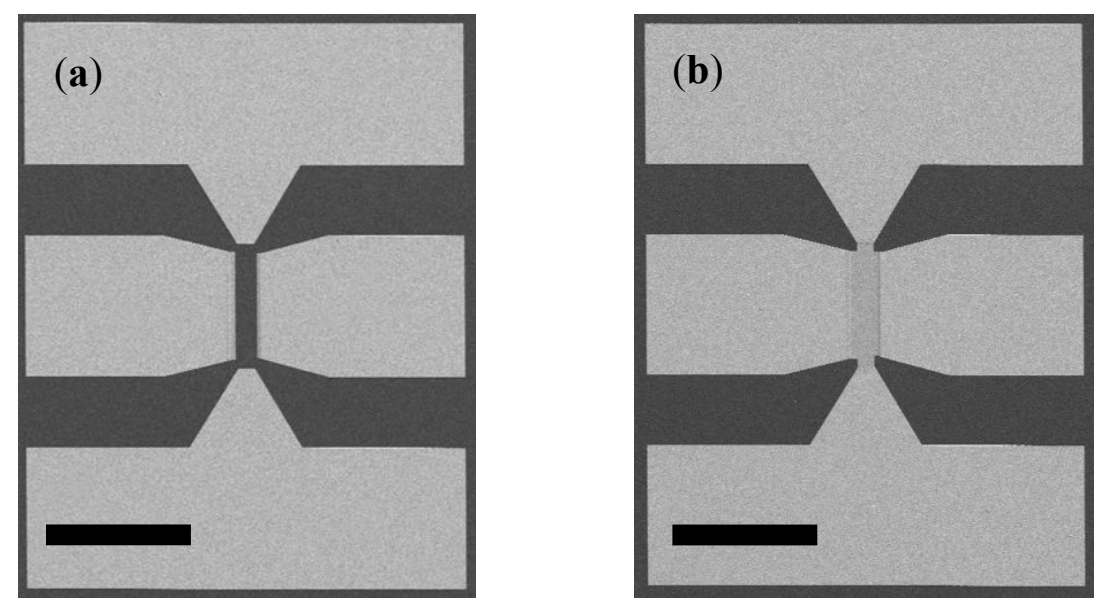

Figure S4 Structures of 'Open' and 'Short' for de-embedding. (a) Extrinsic Open structure. The scale bar is $100 \mu \mathrm{m}$. (b) Extrinsic Short structure. The scale bar is $100 \mu \mathrm{m}$. Extrinsic Open/Short structures were fabricated through using a blank square area/ a metal-deposited square area to replace the transistor region.
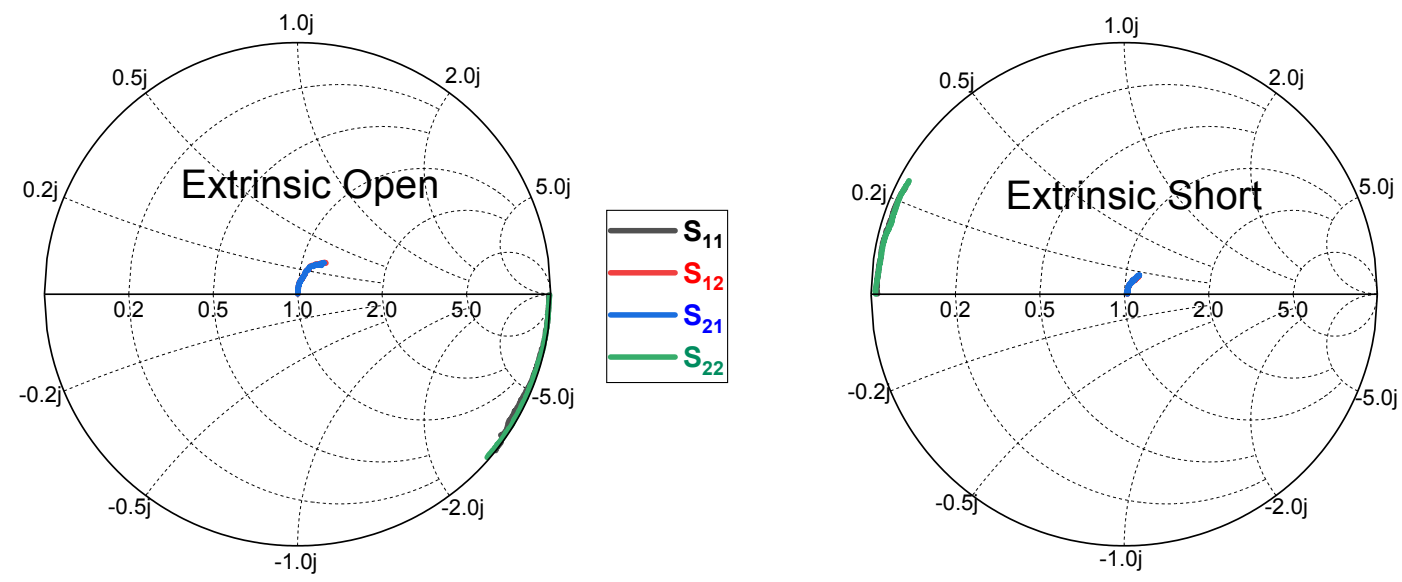

Figure S5 S-parameters of 'Open' and 'Short' structures. All biases were set to zero, and scanning 
frequencies were from $100 \mathrm{MHz}$ to $40 \mathrm{GHz}$ with a linear step of $100 \mathrm{MHz}$.

\section{The extraction of $f_{\mathrm{T}}$ and $f_{\max }$ via S-parameters}

As for the as-measured performance, the $f_{\mathrm{T}}$ is defined as the frequency when current gain $\left(H_{21}\right)$ reaches unity $(0 \mathrm{~dB})$, while $f_{\max }$ is defined as the frequency when power gain $\left(G_{\max }\right)$ reaches $0 \mathrm{~dB}$. The current gain $\left(H_{21}\right)$ and power gain $\left(G_{\max }\right)$ can be calculated using S-parameters by the following equations:

$$
\begin{gathered}
H_{21}=\frac{-2 S_{21}}{\left(1-S_{11}\right)\left(1+S_{22}\right)+S_{12} S_{21}}, \\
G_{\max }=\left|\frac{S_{21}}{S_{12}}\left(K-\sqrt{K^{2}-1}\right)\right|,
\end{gathered}
$$

respectively, where $K$ is the stability factor and given by

$$
K=\frac{1+\left|S_{11} S_{22}-S_{12} S_{21}\right|^{2}-\left|S_{11}\right|^{2}-\left|S_{22}\right|^{2}}{2\left|S_{12} S_{21}\right|} .
$$

As for the de-embedding performance, the de-embedding process includes: (a) Convert Sparameters of a RF transistor, open structure, and short structure to Y-parameters using the equation shown in Table S1; (b) Calculate de-embedding Y-parameters by

$$
Y_{\text {De }- \text { embedding }}=\left(\frac{1}{Y_{\text {DUT }}-Y_{\text {OPEN }}}-\frac{1}{Y_{\text {SHORT }}-Y_{\text {OPEN }}}\right)^{-1}
$$

where, $Y_{\mathrm{DUT}}, Y_{\mathrm{OPEN}}$, and $Y_{\mathrm{SHORT}}$ represent the $\mathrm{Y}$-parameters of a RF transistor, open structure, and short structure; Convert $Y_{\text {De-embedding }}$ to $S_{\text {De-embedding }}$ using the equation shown in Table S1; (c) Calculate current gain $\left(H_{21}\right)$ and power gain $\left(G_{\max }\right)$ from $S_{\text {De-embedding }}$; Extract $f_{\mathrm{T} \text {,ext }}$ and $f_{\max , \text { ext }}$. 
Table S1 The conversions between Y-parameters and S-parameters.

\begin{tabular}{|c|c|}
\hline Y converted from $\mathrm{S}$ & S converted from Y \\
\hline$Y_{11}=\frac{\left(1-S_{11}\right)\left(1+S_{22}\right)+S_{12} S_{21}}{\Delta_{2}}$ & $S_{11}=\frac{\left(1-Y_{11}\right)\left(1+Y_{22}\right)+Y_{12} Y_{21}}{\Delta_{1}}$ \\
\hline$Y_{12}=\frac{-2 S_{12}}{\Delta_{2}}$ & $S_{12}=\frac{-2 Y_{12}}{\Delta_{1}}$ \\
\hline$Y_{21}=\frac{-2 S_{21}}{\Delta_{2}}$ & $S_{21}=\frac{-2 Y_{21}}{\Delta_{1}}$ \\
\hline$Y_{22}=\frac{\left(1+S_{11}\right)\left(1-S_{22}\right)+S_{12} S_{21}}{\Delta_{2}}$ & $S_{22}=\frac{\left(1+Y_{11}\right)\left(1-Y_{22}\right)+Y_{12} Y_{21}}{\Delta_{1}}$ \\
\hline
\end{tabular}

Where, $\Delta_{1}=\left(1+Y_{11}\right)\left(1+Y_{22}\right)-Y_{12} Y_{21}, \Delta_{2}=\left(1+S_{11}\right)\left(1+S_{22}\right)-S_{12} S_{21}$.

Table S2 Comparison of the device parameters for our CNT RF transistors with our previous work $^{17}$

\begin{tabular}{|l|l|l|l|l|l|l|l|}
\hline & $L_{\mathrm{g}}(\mathrm{nm})$ & $R_{\mathrm{g}}(\Omega)$ & $C_{\mathrm{gs}}(\mathrm{fF})$ & $C_{\mathrm{gd}}(\mathrm{fF})$ & $C_{\mathrm{ds}}(\mathrm{fF})$ & $g_{\mathrm{m}}(\mathrm{mS})$ & $R_{\mathrm{ds}}(\mathrm{k} \Omega)$ \\
\hline $\begin{array}{l}\text { Previous } \\
\text { Work }\end{array}$ & 50 & 41 & 5.6 & 4.8 & 2 & 6.2 & 0.4 \\
\hline $\begin{array}{l}\text { This } \\
\text { work }\end{array}$ & 50 & 35.8 & 2.6 & 1.9 & 2.1 & 7.9 & 0.36 \\
\hline $\begin{array}{l}\text { This } \\
\text { work }\end{array}$ & 80 & 22.7 & 4.9 & 4.6 & 1.3 & 8.6 & 0.48 \\
\hline
\end{tabular}

The $R_{\mathrm{g}}, C_{\mathrm{gs}}, C_{\mathrm{gd}}, G_{\mathrm{ds}}, g_{\mathrm{m}}$ and $R_{\mathrm{ds}}$ were calculated according to equations (S1-S5).

$$
\begin{gathered}
Y_{11}{ }^{\prime}=j \omega\left(C_{\mathrm{gs}}+C_{\mathrm{gd}}\right) \\
Y_{12}{ }^{\prime}=-\mathrm{j} \omega C_{\mathrm{gd}} \\
Y_{21}{ }^{\prime}=g_{m}-\mathrm{j} \omega C_{\mathrm{gd}} \\
Y_{22}{ }^{\prime}=1 / R_{\mathrm{ds}}+j \omega\left(C_{\mathrm{ds}}+C_{\mathrm{gd}}\right)
\end{gathered}
$$




$$
\operatorname{Re}\left(Z_{11}-Z_{12}\right)=R_{g}+\frac{A_{g}}{\omega^{2}+B}
$$

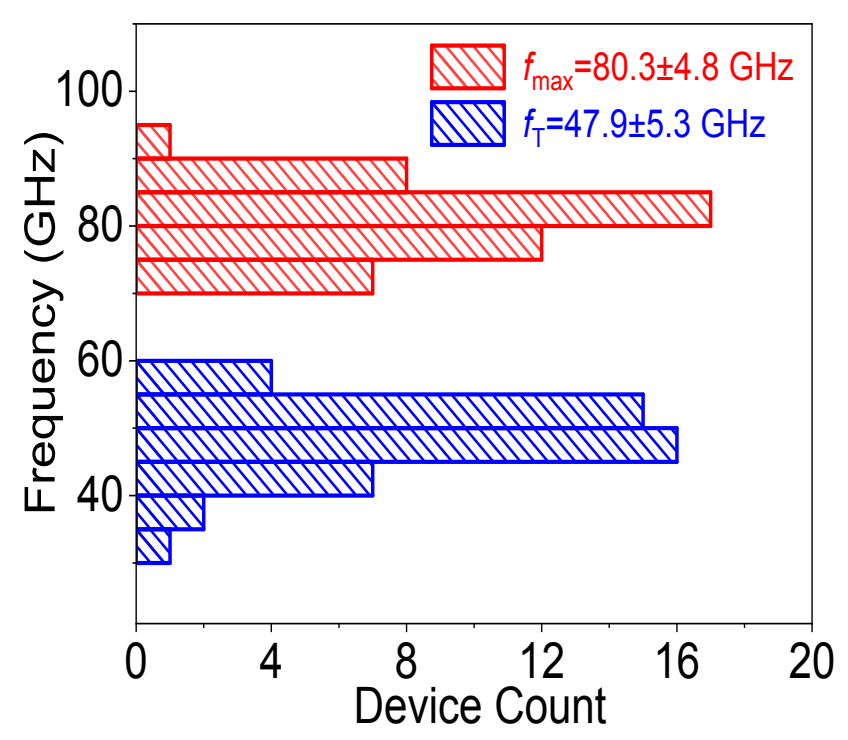

Figure S6. Aggregate data of the as-measured $f_{\mathrm{T}}$ and $f_{\max }$ of the total CNT RF multi-finger transistors with an average $f_{\mathrm{T}}$ of $47.9 \pm 5.3 \mathrm{GHz}$ and $f_{\max }$ of $80.3 \pm 4.8 \mathrm{GHz}$

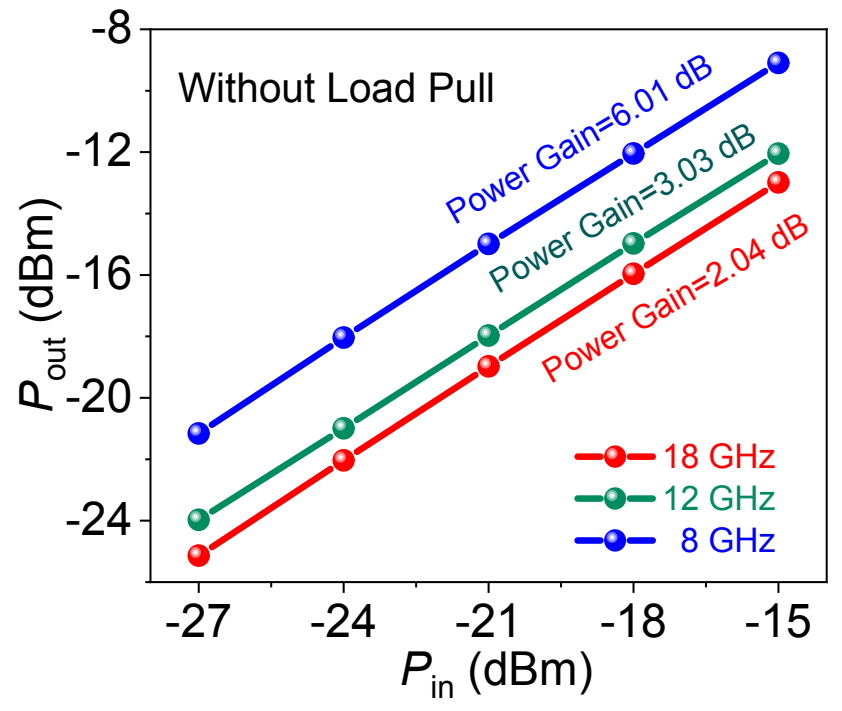


Figure S7. The output power versus input power of the champion CNT amplifier working at $8 \mathrm{GHz}$, $12 \mathrm{GHz}$ and $18 \mathrm{GHz}$ respectively, without load-pull impedance matching.

Table S3 Relation between the DC and RF figures of merit.

\begin{tabular}{|c|c|c|}
\hline$L_{g}(\mathrm{~nm})$ & \multicolumn{2}{|c|}{35} \\
\hline Device Number & $\mathbf{\# 1}$ & $\mathbf{\# 2}$ \\
\hline$g_{m}(\mathrm{mS} / \mu \mathrm{m})$ & $\mathbf{0 . 5 2}$ & $\mathbf{0 . 4 5}$ \\
\hline$C_{g}(\mu \mathrm{F} / \mu \mathrm{m})$ & $\mathbf{0 . 2 8}$ & $\mathbf{0 . 2 8}$ \\
\hline $\begin{array}{c}\text { Estimated } f_{T} \\
\text { by } f_{\mathrm{T}}=g_{\mathrm{m}} / 2 \pi C_{\mathrm{g}}(\mathrm{GHz})\end{array}$ & $\mathbf{2 9 5}$ & $\mathbf{2 5 6}$ \\
\hline As-measured $f_{T}(\mathrm{GHz})$ & $\mathbf{5 8}$ & $\mathbf{5 2}$ \\
\hline Pad de-embedded $f_{T}(\mathrm{GHz})$ & $\mathbf{2 1 2}$ & $\mathbf{1 9 0}$ \\
\hline
\end{tabular}
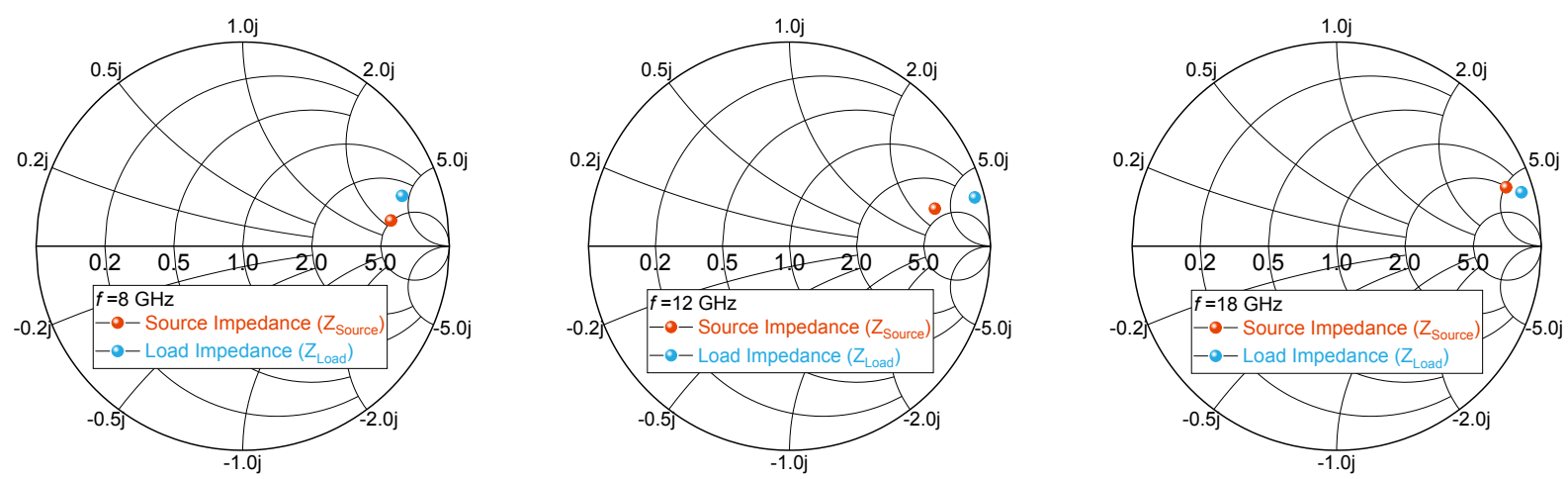

Figure S8. Source and load impedances used in the load-pull measurements at different measure frequency points. 


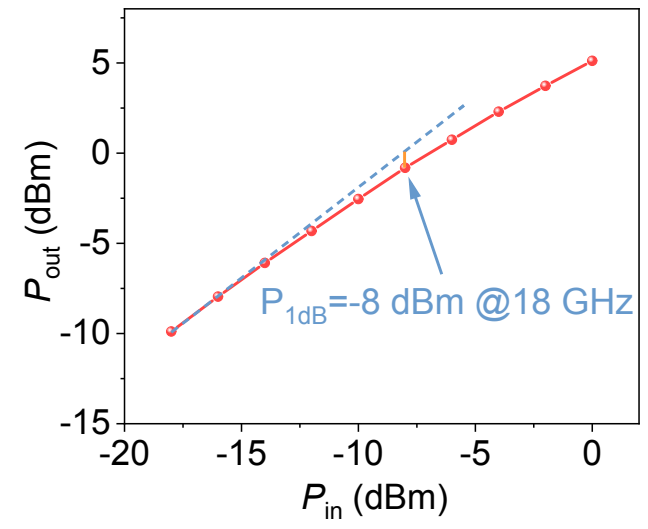

Figure S9. Gain curves from low input power to $\mathrm{P}_{1 \mathrm{~dB}}$ point.

\section{Reference}

(1) Zhong, D.; Shi, H.; Ding, L.; Zhao, C.; Liu, J.; Zhou, J.; Zhang, Z.; Peng, L. M. Carbon Nanotube Film-Based Radio Frequency Transistors with Maximum Oscillation Frequency above $100 \mathrm{GHz}$. ACS Appl Mater Interfaces. 2019, 11 (45), 42496-42503. 